\title{
Stillbirths: Progress and Unfinished Business
}

\section{Authors}

J Frederik Frøen, Ingrid K Friberg, Joy E Lawn, Zulfiqar A Bhutta, Robert C Pattinson, Emma R Allanson, Vicki Flenady, Elizabeth M McClure, Lynne Franco, Robert L Goldenberg, Mary V Kinney, Susannah Hopkins Leisher, Catherine Pitt, Monir Islam, Ajay Khera, Lakhbir Dhaliwal, Neelam Aggarwal, Neena Raina, and Marleen Temmerman, for The Lancet Ending Preventable Stillbirths Series study group

The Lancet Ending Preventable Stillbirths Series study group J Frederik Frøen, Joy E Lawn, Alexander E Heazell, Vicki J Flenady, Mary V Kinney, Luc de Bernis, Hannah Blencowe, Susannah Hopkins Leisher

\section{Affiliations}

Department of International Public Health, Norwegian Institute of Public Health, Oslo, and Center for Intervention Science for Maternal and Child Health, University of Bergen, Norway (J F Frøen, MD, PhD); Department of International Public Health, Norwegian Institute of Public Health, Oslo, Norway (I K Friberg, PhD); Maternal Reproductive \& Child Health (MARCH) Centre, London School of Hygiene \& Tropical Medicine, London, UK (J E Lawn, MD); Centre for Global Child Health, Hospital for Sick Children, Toronto, Canada, and Center of Excellence in Women and Child Health, the Aga Khan University, Karachi, Pakistan (Z A Bhutta, MD, PhD); SAMRC Maternal and Infant Health Care Strategies unit, Department of Obstetrics and Gynaecology, University of Pretoria, Pretoria, South Africa (R C Pattinson, MD); School of Women's and Infants' Health, Faculty of Medicine, Dentistry and Health Sciences, University of Western Australia, Crawley, Australia and UNDP/UNFPA/UNICEF/WHO/World Bank Special Programme of Research, Development and Research Training in Human Reproduction, Department of Reproductive Health and Research, World 
Health Organization, Geneva, Switzerland (E R Allanson, MBBS); Mater Research Institute - The University of Queensland (MRI-UQ), Brisbane, Australia, and International Stillbirth Alliance (Vicki Flenady, PhD and S H Leisher, MA); Research Triangle International, Durham, NC, USA (E M McClure, PhD) ; EnCompass LLC, Rockville, MD, USA (L Franco, ScD); Department of Obstetrics and Gynecology, Columbia University, New York, NY, USA (R L Goldenberg, MD); Save the Children, Saving Newborn Lives, Edgemead, South Africa (M V Kinney, MSc); Department of Global Health \& Development, London School of Hygiene \& Tropical Medicine, London, UK (C Pitt, MSc); WHO Country Office, Windhoek, Namibia (M Islam, MD); Ministry of Health \& Family Welfare, Government of India, Delhi, India (A Khera, MD); Department of Obstetrics and Gynecology, Postgraduate Institute of Medical Education \& Research, Chandigarh, India (L Dhaliwal, MD and N Aggarwal, MD); Department of Child and Adolescent Health, WHO regional office for South-East Asia, Delhi, India (N Raina, MD); Department of Reproductive Health and Research, World Health Organization, Geneva, Switzerland ( $M$ Temmerman, MD, PhD)

Correspondence to: Box 4404 Nydalen, N-0403 Oslo, Norway 
This first paper of The Lancet Ending Preventable Stillbirth Series reviews progress in critical areas, identified in the 2011 call to action for stillbirth prevention, to inform the integrated post-2015 maternal and newborn health agenda. Global attention to babies who die in stillbirth is rapidly expanding, from integration within the new Global Strategy for Women's, Children's, and Adolescent's Health, to country policies inspired by the Every Newborn Action Plan. Supportive new guidance and metrics including stillbirth as a core health indicator and measure of quality of care are emerging. Ensuring integration of action for prenatal health - the biological foundation of life-long health - within the continuum of care for maternal and newborn health is becoming a key priority. Still, specific actions for stillbirths remain needed for advocacy, policy formulation, monitoring and research, including remedying the dearth of data on effective coverage of proven interventions for prenatal survival. Stronger leadership is needed globally and in countries, and institutions with a mandate to lead global efforts for mothers and their babies must assert their leadership to reduce stillbirths by promoting healthy and safe pregnancies.

\section{Keywords}

Stillbirth, Maternal health, Newborn health, Prenatal health, Prevention, Antenatal care, Care at 
The past 15 years saw historic achievements for women's and children's health ${ }^{1}$. Yet, 2.7 million women experience the death of their babies in stillbirth in the last trimester of pregnancy or during labour $^{2-5}$

In 2011, the Lancet Stillbirth Series (LSS) reviewed the status of stillbirths ${ }^{2,6}$ and evidence for cost effective interventions that could save 1.1 million babies annually $y^{7,8}$ and provide triple return on investments by preventing newborn and maternal deaths ${ }^{9}$. The call to action covered critical activities for stillbirth reduction ${ }^{10}$ : international and country prevention targets, improved monitoring of stillbirth, their causes and disparities, inclusion of stillbirth prevention in maternal and newborn health $(\mathrm{MNH})$ plans and research, and action against stigma which adds burden to families and hampers societal engagement.

That series received wide press coverage, reaching almost one billion people and generating significant response not just from academia and organisations, but also from the public ${ }^{11}$. Yet, unlike efforts for maternal and newborn survival ${ }^{1,12,13}$, no systematic progress monitoring followed. Global health policy changes are typically observed over many years ${ }^{14,15}$, but despite limited time for operationalization of the United Nations (UN) Sustainable Development Goals (SDG) ${ }^{16}$, the Global Strategy for Women's, Children's and Adolescent's Health (Global Strategy) ${ }^{17}$, and its supporting Global Financing Facility (GFF) ${ }^{18}$. Our findings in this series inform a renewed call to action ${ }^{19}$. In this first paper of the Lancet Ending Preventable Stillbirths Series ${ }^{4,19-21}$, the objective is to review progress in critical areas identified in the 2011 call to action ${ }^{10}$. We adopted a heuristic approach to policy analysis used in $\mathrm{MNH}^{15}$ to learn from how other initiatives created change $\mathrm{e}^{15,22-25}$, supplemented with a framework of determinants of global health political priority, to explore why stillbirths are prioritized, or why not ${ }^{22}$ (figure 1 ). We review five domains: moving stillbirth onto the global MNH agenda, formulating global and national policies, funding and implementing programs, 
developing capacity for monitoring and research, and the role of leadership and partnerships. For the latter, we draw on a global health network framework previously applied to newborn mortality ${ }^{26,27}$. Data sources are presented in panel 1 , with detailed methods and additional results in the webappendix.

\section{Agenda setting and prioritization}

The LSS exposed a gulf between the stillbirth burden and its invisibility on the global MNH agenda ${ }^{2,6}$, and called on the international community to include stillbirths in all relevant health reports and initiatives ${ }^{10}$. Agenda setting is crucial, as demonstrated by country actions for MNH that followed the policy norms advanced by the Millennium Development Goals (MDGs) and the 2010 Global Strategy hampered prioritization of stillbirth, and called on stakeholders to address barriers in "Political context" and "Actor power" (figure 1) 2,10. $^{2}$

Key messages in the LSS on "Issue characteristics" presented stillbirth rate and cause estimates as credible indicators of burden ${ }^{3,6,30}$, and evidence for simple and cost-effective preventive interventions to integrate in health systems ${ }^{7-9}$. "Ideas" included portrayal of stillbirths as a neglected issue, with devastating and stigmatizing losses of babies for mothers and fathers that need to be counted. Aligned with the emerging norm of an integrated continuum of care for the inextricably linked mother and baby ${ }^{31}$, stillbirths were recognized as babies dying of preventable causes, especially intrapartum, which were inseparable from major causes of maternal and newborn deaths. The LSS added rate, cause, and intervention effectiveness estimates into the Lives Saved Tool $\left(\right.$ LiST) ${ }^{32}$, to report a triple return on investments for integrated stillbirth, maternal and newborn mortality prevention (figure 1 , table 1$)^{7}$. To assess evidence of adoption of "Ideas" and "Issue characteristics" presented in the LSS in the activities and new initiatives of global MNH agencies, commissions and partnerships, a 
continuum of quality care for the interlinked mother and baby remains a widely adopted theme,

particularly present in new initiatives. While all documents including stillbirth did so in a broader MNH context, these themes had little correlation with stillbirth priority, neither in qualitative or quantitative analyses. Of all "Ideas", the "triple return on investment", implicitly acknowledging the burden, lives lost, and interlinked causes and solutions, was most frequently adopted. All subsequent MNH documents using investment cases include stillbirths averted, even when this was the only mention of stillbirth ${ }^{18}$. Additional common themes include presentation of cost-effective themselves to create priority. None addressed stigma associated with stillbirths. In initiatives with explicit calls for stillbirth prevention or targets, two correlated portrayals stand out. First, stillbirths are humanized as babies that die, rather than only enumerating them as stillbirths. Second, prenatal and newborn health is presented as an inseparable continuum, whether in pathology (shared pathophysiology with preterm birth, low birth weight and newborn deaths) or health (prenatal biological potential for health). These must be reinforced to overcome pervasive barriers identified in the LSS: the stigma that impedes women's voice, and the fatalism that stillbirths, as previously for newborn deaths ${ }^{27}$, are not amenable to prevention, and are lesser losses than newborn deaths $\mathrm{s}^{2,12,21}$. MDG targets for maternal and child deaths reflecting the dominating "supernorm" shaping policy attention kept stillbirths barely visible ${ }^{29}$. The major UN agencies pursued a joint mission to "ensure that health plans are MDG-driven and performance-based"33. The reports' objectives were to convey efforts to achieve the MDGs, and compliance with recommendations to support these goals. In the MDG race, there was little opportunity to include stillbirths which did not directly count towards the targets, unlike newborns. Only the "unfinished business" stillbirth theme was related to the MDGs (web-appendix). 
The LSS influenced discussions for the post-2015 agenda, onto which stillbirth rapidly emerged. "Born Too Soon" (2012), the multi-stakeholder global action report on preterm birth, highlighted the

stillbirth burden presented in LSS, and the shared nature of causes and solutions with preterm births $^{34}$. Global agencies, donors and MNH organizations, led by UNICEF and WHO, presented "Every newborn: an action plan to end preventable deaths" (ENAP) to the WHO Executive Board in $2014^{35}$, integrating intrapartum stillbirth prevention ${ }^{36}$. Countries, individuals, professional associations and non-governmental organizations engaged strongly in consultations, and countries specifically requested stillbirth prevention targets ${ }^{37}$. The World Health Assembly (WHA) endorsed ENAP, requesting progress reports towards targets, and urged member states to implement these policies and strengthen monitoring ${ }^{38}$. In parallel, the independent Expert Review Group, a UN initiative monitoring accountability for women and children, called to integrate stillbirth in the post-2015 agenda ${ }^{12,39}$. It requested a Global Investment Framework for Women's and Children's Health, the precursor of the GFF to support the Global Strategy, both incorporating stillbirths in their investment cases based on LiST ${ }^{18,40}$. The UNFPA's 2014 State of the World's Midwifery and The Lancet Midwifery Series underlined midwifery's role in preventing stillbirths ${ }^{41,42}$, which was reiterated in the Strategies towards Ending Preventable Maternal Mortality (EPMM), endorsed by the global agencies, donors and professional organizations, calling for stillbirth monitoring, and setting "to protect and support the mother-baby dyad" as a guiding principle for action ${ }^{43}$. ENAP and EPMM subsequently promoted integrated strategies covering the full continuum of care ${ }^{44}$. The 2015 progress report for the 2010 Global Strategy for Women's and Children's Health, identified stillbirths as a neglected area for future priority action ${ }^{28}$.

Many aspects of the LSS' framing of stillbirth have thus resonated with global MNH initiatives, reflected by firm integration of stillbirth in the 15 scoping papers for the Global Strategy ${ }^{44-46}$. Many organizations have endorsed new initiatives reflecting a shift towards priority for stillbirth, compared with their previous activity reports (web-appendix). The Global Strategy has been subjected to wide country and public consultations, coordinated by The Partnership for Maternal, Newborn and Child 
Health (PMNCH), a global partnership of UN agencies, donors, professional and civil society organizations. It envisions "An end to preventable maternal, newborn, child and adolescent deaths and stillbirths", presents the stillbirth burden among key "Child health challenges", humanizes stillbirth as "2.6 million babies [who] die", lists essential interventions for prevention, and takes a lifecourse approach recognizing that "Everyone is conceived with a unique biological potential for health"17.

Similar themes were reflected in interviews of representatives of 33 organizations working in $\mathrm{MNH}$, including the need for integration within the broader $\mathrm{MNH}$ agenda, integrated quality care for $\mathrm{MNH}$, clear and sensitive messaging to counter stigma associated with stillbirths, and framing stillbirth prevention in a continuum with newborn health (web-appendix). While our document review found that evidence presented in the LSS has been widely adopted by global MNH initiatives, agencies, commissions and partnerships, respondents raised concerns that insufficient evidence and information on rates, causes and cost-effective solutions are available in low and middle income countries (LMIC) to support country-level prioritization - themes identified in the LSS as key to overcome perceived futility of prevention ${ }^{2}$. Supporting the appropriateness of a global discourse humanizing babies that die, none presented concerns for stillbirth prevention being in conflict with reproductive rights when asked for key challenges to the community working on stillbirths - in accordance with the LSS findings that abortion issues were unrelated to stillbirth priorities in LMIC ${ }^{2}$. The shift in priority for stillbirth globally from a prolonged period of stability (largely driven by the MDGs), is taking a form seen in several other global health issues ${ }^{14}$; a disruptive burst of rapid transformation by a new policy conceptualization in the presence of a policy venue (the processes toward the Global Strategy). Yet, many opportunities have been missed for integration of stillbirth in new MNH initiatives, including acknowledging the burden, promoting essential interventions, and call for monitoring of stillbirth (web-appendix). This new priority will only matter if followed by policies, funding, and country adoption, but as this transformation is just barely completed, limited policy formulation and program implementation should be expected. 


\section{Policy formulation and program implementation}

The LSS recommended interventions for integration into policies and programs for prenatal health across the continuum of care ${ }^{7,8}$, as well as systems approaches such as perinatal audits, birth planning and transportation ${ }^{9,10}$, and actions to reduce stigma ${ }^{2,4,5,10,19}$.

New policies are emerging. Partly based on the failure of previous policies to prevent stillbirths ${ }^{47-49}$, the WHO is revising guidance for antenatal care, including antepartum stillbirth as a quality of care indicator, based on 57 systematic reviews including stillbirth among key outcomes of interventions and care models. The $\mathrm{WHO}$ recently published a framework for quality of care in $\mathrm{MNH}^{50}$, and is preparing standards and indicators which will include antepartum and intrapartum stillbirths as core indicators for high quality antenatal care and care at birth, respectively. Also, the WHO is preparing guidance for audits to assess causes and preventability of stillbirths and newborn deaths. All are expected in 2016.

Some countries' policies for stillbirth have changed rapidly, mostly driven by ENAP providing programmatic guidance ${ }^{36}$. In ten months (March 2015), 39 LMIC had provided commitments to it ${ }^{51}$. In India, the adoption of key themes from the LSS, global advocacy, national leadership and champions, and allies in MNH providing evidence for feasibility of national monitoring and prevention were all instrumental for implementation (Panel 3). Among the ten countries contributing $65 \%$ of stillbirths globally ${ }^{4}$, five have, by August 2015, written or are writing "sharpened" MNH plans inspired by ENAP, with four including stillbirth reduction targets (web-appendix). Enforcement and funding associated with these plans vary, and many devolve implementation to sub-national levels. Of the remaining five countries, only one included a stillbirth target in their most recent MNH plan. The targets set by the five countries, if met, would represent a reduction of stillbirths globally by one fourth. Yet, some countries specifically omit stillbirth from their newborn action plans, due to cultural norms of stillbirth as a lesser concern than newborn deaths (personal communications). 

recently than 2011 (web-appendix). Interventions recommended by the LSS were modestly addressed: $12 \%$ mentioned folic acid supplementation, $26 \%$ syphilis detection and treatment, $66 \%$ caesarean sections and comprehensive emergency obstetric care and $24 \% \mathrm{MgSO}_{4}$ for eclampsia.

Community actions, such as birth planning and transportation, social and bereavement support, and addressing stigma, have only been captured if preceded by concerted national policy. So while our findings underestimate community action, hardly any health plans promoted such activities. None responded to the LSS calls to act against stigma and provide bereavement support. The LSS called for empowerment of women and families, but while acknowledging that stigma can prevent women from realizing their reproductive rights, none of the key UN entities working for the empowerment and rights of women address stigma, taboos and abuse after stillbirth or newborn death ${ }^{52-55}$, and global efforts to promote better mental health have no focus on such topics ${ }^{56}$.

Being outside the MDG norms, hardly any funding from donors reporting to the Organization for Economic Cooperation and Development's database has targeted stillbirth prevention. Funding to women's and children's health has increased substantially under the MDGs, and compared with the US9.5\$ billion disbursed in 2013 alone ${ }^{57}$, only four projects mentioned stillbirth in the entire 12-year funding period (2002-13) and only two of them funded program implementation - for a total of US $10.6 \$$ million. Over that same period, more than 80 projects on malaria in pregnancy, and 35 on syphilis, were also funded, but their impacts on stillbirth remained unstated.

\section{Monitoring and research}

For the global MNH community to coalesce effectively around stillbirth prevention, lessons from maternal and newborn mortality ${ }^{22-25}$ indicate the need for agreement on credible measures of burden and causes, a classification to present them, and evidence for simple and cost effective interventions with indicators for monitoring (figure 1). 
While stillbirths have not been on the agenda, strengthening of civil registration and vital events systems has ${ }^{28}$. Data sources for the new global estimates of stillbirths, the first since 2011, 68 in $2009^{5}$. Further improvements are expected with stillbirths recently included in the WHO 100 Core Health Indicators ${ }^{58}$ and the UN Inter-agency Group for Child Mortality Estimation's monitoring program $^{51}$. At the 2015 WHA, the slow reduction of stillbirths was reported with the MDGs for the first time, due to reporting requirements for $\operatorname{ENAP}^{38,51,59,60}$. While the LSS came in time to influence the Global Strategy, selection of the SDG targets, starting in 2012, was guided by political recommitment to the MDGs ${ }^{16}$. The SDGs likewise have targets for maternal and child mortality, not stillbirth $^{16}$. The Global Strategy and GFF, politically committed to support the SDGs, therefore do not include stillbirth targets ${ }^{17,18}$.

Dissimilar stillbirth definitions continue to hamper head-to-head comparisons ${ }^{4,5}$. A full $41 \%$ of data in the global estimates rely on definitions other than the WHO's ${ }^{5}$. Rights and care in pregnancy rely on gestational age while the WHO's stillbirth definition relies on birth weight ${ }^{61}$. This does not fit national legislation or data, and WHO refrained from using their definition for the global stillbirth rates, targets, and 100 Core Health Indicators ${ }^{5,36,58}$. Disaggregated data are scarce. Only $36 \%$ of countries reported intrapartum mortality rates, and fewer still, causes of death ${ }^{4,5,62,63}$. Subsequent to the LSS call for a global classification ${ }^{2,6,8,10}$, the WHO collaborated with scientific groups to inform a new approach to perinatal mortality classification ${ }^{62-64}$ using the International Classification of Disease (ICD PM), modelled on the maternal mortality classification (ICD MM) ${ }^{65}$ and expected for publication in $2016^{66}$. The LSS reported that ICD-10 does not capture important fetal and placental categories for stillbirths ${ }^{6}$, and the 2018 revision of ICD-11 must address this underlying weakness. Capacity to identify causes of death may have been weakened. While the 2007 WHO Verbal Autopsy Tool adequately defined newborn deaths and stillbirths by time of death, with multiple causes, the 2012 revision requires reporting stillbirth as the cause of stillbirth ("fresh" or "macerated") ${ }^{67,68}$. With this guidance, verbal autopsies cannot inform ICD PM appropriately. 
Monitoring effective interventions with population-based data remains an immense gap. Contact with care providers does not equal having received any of the interventions LSS recommended, nor signal functions of basic and comprehensive emergency obstetric care, which constitute effective coverage of quality care ${ }^{7,69}$. Current estimates are largely based on household surveys with few indicators on effective coverage beyond intermittent prevention of malaria in pregnancy, insecticide treated bed-nets, and caesarean section rates (table 2 ), and only a subset of LMIC ( $54 \%, 58 \%$ and 10\%, respectively) have had a national survey including these indicators after 2011. indicators, tools, and institutionalization in national and global metrics architecture ${ }^{70}$. A direct response to the LSS and the accountability agenda was an initiative by the WHO and Norwegian Institute of Public Health to strengthen health information systems, specifically electronic health registries tracking women and children across the continuum of care $\mathrm{e}^{71,72}$. This "eRegistries" framework integrates process and outcome indicators ${ }^{73}$, including stillbirth, for screening and management of Essential Interventions, Commodities and Guidelines for Reproductive, Maternal, Newborn and Child Health, as well as guidance for electronic solutions ${ }^{74}$, and ethical governance of data $^{75}$. Sustainable electronic health information systems are now widespread across LMIC $^{76}$ with 27 having written eHealth strategies, half specifically in support of women's and children's health ${ }^{77}$. Electronic solutions create unprecedented opportunities ${ }^{72,76,78,79}$, potentially combining health records for care providers with a back-end registry for public health monitoring and targeting ${ }^{71,72}$. According to a survey of public health officials from LMIC, four of five responders report that they are registering data on pregnancy, birth and child health - three quarters in transition using both paper and electronic reporting ${ }^{72}$. The new global roadmap for Measurement and Accountability for Results in Health specifically commits to closing the gaps in MNH data for effective coverage and accountability for every baby. First, civil registration should register all births, and second, health information should be collected electronically in real-time where they are created, in communities 
and facilities, including integrated maternal and perinatal surveillance and response - in all countries

288 by $2030^{80,81}$.

The LSS identified research priorities, but standard search functions proved inefficient to assess alignment with them, as many were complex combinations and subsets of ideas ${ }^{10}$. Qualitative analysis tools found only $11 \%$ of abstracts related to stillbirth to be potentially linked to LSS priorities, but with significantly greater concordance in LMIC (web-appendix). Although the stillbirth research volume increased three-fold since 2000 , the level is only $20 \%$ of research relating to newborns which increased similarly. The greatest relative increase on stillbirth research was in LMIC. The annual number of registered trials for $\mathrm{MNH}$ including terms relating to stillbirth increased by $26 \%$. Total funding for stillbirth-focused research from eleven of the largest research funders amounted to $\$ 50 \mathrm{~m}$ between 2012 and 2014, constituting only 3\% of overall MNH research funding. Compared to average annual funding over 2006-10, research funding for MNH has remained flat while stillbirthfocused research increased by 22\%, suggesting a potential increased focus by funders since 2011 (web-appendix).

\section{Leadership and partnerships}

Strong leadership and partnerships are needed to ensure change for prenatal health and survival ("Actor power", figure 1). Global health network studies find that the emergence and effectiveness of leaders and networks is shaped by issue characteristics and political context ${ }^{26}$. Stillbirth has severe consequences and is tractable, issue characteristics (Table 1) that typically strengthen networks, as does the policy environment of potentially strong allies with interests that align. Simultaneously, funding gaps and exclusion of stillbirths from the policy "supernorms" advanced by the MDGs have hampered the effectiveness of a global stillbirth network ${ }^{26}$. A moment of opportunity to influence decision makers was essential to create priority for maternal mortality ${ }^{22,29}$, as may now exist for 
health networks are drawn upon to explore the stillbirth network: leadership, governance, composition, and framing strategies ${ }^{26}$.

The 2011 LSS originated from an initiative by the leadership in the International Stillbirth Alliance, an then WHO Department for Making Pregnancy Safer. With leadership from The Lancet's Editor, a group of individual scientists was assembled to develop the series, including scholars in global MNH policy. These previously disconnected groups, together with donors and others specifically approached to support the development and dissemination of the LSS, created the core of the current global stillbirth network of 33 organizations working in $\mathrm{MNH}$ assessed by an organizational network analysis presented in this series ${ }^{19}$. The context of publishing deadlines for the LSS forced the emerging network of parental, scientific, and policy groups to coalesce rapidly on the framing strategies and themes published in the LSS (table 1).

The network appears to be expanding. The organizational network analysis identified the most highly connected organizations in the network in terms of stillbirth work ${ }^{19}$. Yet, on a formal organizational level, several had paid only minor attention to stillbirths prior to the policy opportunity of the Global Strategy, according to their activity reports. Insufficient organizational commitment to stillbirth issues was a key theme in the qualitative interviews with organization representatives, as the network continues to be generally dependent on a small group of committed individuals rather than their overall organizations. Respondents also reported a lack of strong political voice and individual advocates in the public domain; in particular, they wished for a stronger presence of parental groups and voices in the broader stillbirth network (web-appendix).

The diverse composition of the network created opportunities ${ }^{26}$, but the predominant composition of scientists and professionals, with insufficient inclusion of political and civil society actors, is a weakness hampering progress for country implementation of action, similar to newborns ${ }^{27}$. Additionally, the organizations do not exploit the network efficiently. Among 33 organizations 
surveyed, on average each organization only interacted (for example communications, meetings, or

337 joint action) with one fifth of potential partners on stillbirth-related issues. Maternal and newborn-

338 related interactions between these same organizations exhibited three times the number of

339 connections on average ${ }^{19}$.

340 This network created for the LSS was not a concerted effort by the global MNH community that

341 should have had ownership of the issue. Without a formal governance structure, leadership is

342 currently shared by individuals, mostly not the top leadership of organizations. The LSS was not

343 based on commitments from the leadership of UN agencies, nor did it call for them to assume their

344 global governance responsibility ${ }^{10}$. A key challenge reported by the organizations' representatives

345 was that agencies such as WHO had not yet assumed the leadership role seen for the rest of the

346 MNH field. But the policy environment is in flux, both in norms and allies. With stillbirths integrated

347 in the Global Strategy, and the reporting requirements ENAP, the UN now has mechanisms for

348 holding its agencies accountable for leadership and governance for stillbirth.

\section{Progress and unfinished business}

We find clear progress in agenda setting and prioritization (table 1). While leadership for stillbirth has

been too weak to overcome the barrier of the MDG supernorm, the shift of norms and integration in

the Global Strategy may be a turning point for the neglect of stillbirth. Uptake of themes from the

LSS in the global discourse helps explain why stillbirths have ascended on the agenda, but also points to themes with insufficient adoption, such as recognition that stillbirths are babies that die, and that prenatal health is the biological foundation of life-long health for every newborn. This suggests a communication concern for political priority. Sources reviewed strongly emphasized effective integration of stillbirth within existing MNH priorities and programs, as did the $\mathrm{LSS}^{2,9,10}$, and our interview respondents. Currently, the global MNH discourse, naturally, is predominantly about health, not death (Figure 2). All new initiatives go beyond survival. They are "... for maternal health", "... for newborns to survive and thrive". Stillbirth appears hard to fit in the positive health discourse, 
and is relegated to mortality sections - often as a literal appendix: “... maternal and newborn

mortality" (... "and stillbirth"). This potential misconception of a poorly integrated "add-on" matters.

Stillbirth prevention calls for integrated action for prenatal health and survival from periconception through pregnancy and childbirth ${ }^{2,7-10}$. Concerted communication that stillbirth prevention is promotion of prenatal health is needed: prenatal health relates to stillbirth exactly as neonatal and maternal health relate to neonatal and maternal death. Supporting prenatal health through high quality antenatal and intrapartum care protects and supports the mother-baby dyad ${ }^{43,50,82}$, and represents a quadruple return on investments, saving mothers and newborns, and preventing We find progress in global policies and program guidance, and crucially, the Global Strategy combines the policies of ENAP and EPMM ${ }^{17,44,46}$ with action for the continuum of prenatal health to include prevention of the antepartum majority of stillbirths; without it, the global targets ${ }^{19,36}$ cannot be met even by reducing intrapartum deaths by two thirds $s^{4,5}$. While integration is the only way forward for health systems, clients and providers, the country implementation of ENAP-inspired policies, both as a successful vehicle to introduce stillbirth reduction targets, and conversely, with examples of specific omission of stillbirths, exemplifies that coordinated but specific action for stillbirths remains needed for advocacy, policy formulation, monitoring and research. Women's rights and mental health groups should be engaged. Cultural mores of indifference towards stillbirth must be countered: prenatal health matters for the entire life-course, stillbirth prevention is prenatal health promotion, and to mothers, stillbirths are not numbers, but babies that die. The assumption that stillbirth mortality will automatically decline in parallel with maternal and neonatal mortality without focus is false; the annual reduction rate for stillbirths (1.8\%) the last 15 years is significantly smaller than for newborn (3.1\%) and maternal (3.4\%) mortality ${ }^{4}$. adopted perinatal audit which can reduce perinatal mortality if conducted appropriately ${ }^{83-85}$. There is no action against stigma or for support of affected families. 
The mortality impact of interventions shown with LiST in this series ${ }^{21}$ exemplifies the need for cause of death data to allow policy makers to develop investment and action plans ${ }^{86}$. Conversely, the exclusion of stillbirths in the Global Burden of Disease, Disability-Adjusted Life Years and QualityAdjusted Life Years, restricts cost-effectiveness analyses and impedes the generation of evidence for investment in $\mathrm{MNH}^{86}$.

Stillbirth is included in MNH investment cases, but so far with no accountability: no funding of substance has materialized. An increased traction of the "triple return on investment" within country level policies is plausible as GFF financing of programs requires an investment case ${ }^{18}$, and the UNrecommended OneHealth Tool incorporates LiST calculations for stillbirth ${ }^{18}$. Progress exists in metrics for monitoring and research of stillbirth, but there is still far too little and infrequent monitoring and evaluation to support country advocacy for priority and action ${ }^{31}$. A universally adopted definition of stillbirth is needed, as well as a global repository to access such data. The ongoing revision of ICD 10 to ICD 11 should be an opportunity to formally revise the WHO definition.

Stillbirth prevention through high quality care needs strengthened health systems, effective coverage, and health information systems $s^{7,9,10,19,50,87}$. Countries monitoring stillbirth rates for progress towards targets will benefit from uniquely specific, sensitive, measurable, and actionable indicators of effective coverage - antepartum stillbirth for antenatal care and health promotion, and intrapartum stillbirth for care at birth ${ }^{7,88,89}$. The call to action for Measurement and Accountability for Results in Health sees health information systems as an integrated part of health systems, and health information flowing seamlessly at all levels of the health system as critical for quality of care. Care should be taken to select indicators which support countries' efforts to build sustainable actionable health information systems at point of care, rather than undermining them with indicators only available through household surveys $s^{50,71}$. 
Our findings on the status of research are promising, including stronger growth of research activities, and better alignment with research priorities in LMIC. Nonetheless funding for stillbirth research remains incommensurate with burden.

The global stillbirth network emerged with the LSS, but leadership still needs purposeful development, in particular to ensure country uptake. Institutions with the mandate to lead global efforts for $\mathrm{MNH}$ are not as central as desired, and organizations must commit strongly, not rely on committed individuals. Until now, the core global governance structure of the UN and partnerships

\section{Contributors}

JFF drafted the manuscript and led the review and analysis of reports and initiatives with IKF and SHL. IKF led the review and analysis of health plans, survey instruments, and research efforts and funding with CP. LF led the organizational network analysis and interviews. CP led the review and analysis of donor funding. AK, LD, NA, and NR compiled and reported the implementation of INAP. All authors commented and contributed to the content of the report, and read and approved the final version. JFF had full access to all the data in the study and had final responsibility for the decision to submit for publication.

\section{Conflicts of interest}

We declare that we have no conflicts of interest.

\section{Acknowledgements}

We thank Aleena Wojcieszek for her extensive coordination and technical support for the Lancet Ending Preventable Stillbirths Series, Zachariah J. Falconer-Stout and Kelsey Simmons for their contributions to the organizational network analysis, Wenche Jacobsen and Birgit Vartdal for their 
group for their valuable inputs to the concepts of this paper.

The views expressed in this article do not necessarily represent the decisions, policy, or views of the authors' affiliations.

JFF and IKF were funded in part by a technical support grant from the Norwegian Agency for

Foundation. EA was funded as a PhD candidate at the University of Western Australia by an

Australian postgraduate award, and an Athelstan and Amy Saw Medical top-up scholarship, and by

the Women and Infants Research Foundation with a Gordon King Doctor of Philosophy scholarship.

\section{References}

1. Countdown to 2015. Maternal, Newborn \& Child Survival. Fulfilling the Health Agenda for Women and Children. The 2014 Report: World Health Organization, Geneva, Switzerland, 2014.

2. Frøen JF, Cacciatore J, McClure EM, et al. for the Lancet Stillbirth Series steering committee. Stillbirths: why they matter. Lancet 2011; 377(9774): 1353-66.

3. Cousens S, Blencowe H, Stanton C, et al. National, regional, and worldwide estimates of stillbirth rates in 2009 with trends since 1995: a systematic analysis. Lancet 2011; 377(9774): 131930.

4. Lawn JE, Blencowe H, Waiswa P, et al. for the Lancet Ending Preventable Stillbirth study group. Stillbirths: data for accelerating progress towards 2030. The Lancet (Submitted) 2015.

5. Blencowe H, Lawn JE, Say L, et al. Global, regional, and national estimates of stillbirth rates from 2000 - 2015: an updated systematic analysis. The Lancet Global Health (Submitted) 2015.

6. Lawn JE, Blencowe H, Pattinson R, et al. for the Lancet Stillbirth Series steering committee. Stillbirths: Where? When? Why? How to make the data count? Lancet 2011; 377(9775): 1448-63.

7. Bhutta ZA, Yakoob MY, Lawn JE, et al. for the Lancet Stillbirth Series steering committee. Stillbirths: what difference can we make and at what cost? Lancet 2011; 377(9776): 1523-38.

8. Flenady V, Middleton P, Smith GC, et al. for the Lancet Stillbirth Series steering committee. Stillbirths: the way forward in high-income countries. Lancet 2011; 377(9778): 1703-17.

9. Pattinson RC, Kerber K, Buchmann E, et al. for the Lancet Stillbirth Series steering committee. Stillbirths: how can health systems deliver for mothers and babies? Lancet 2011; 377(9777): 1610-23. 
10. Goldenberg RL, McClure EM, Bhutta ZA, et al. for the Lancet Stillbirth Series steering committee. Stillbirths: the vision for 2020. Lancet 2011; 377(9779): 1798-805.

11. The Lancet. It happened to me: responses to the Stillbirths Series. The Lancet 2011; 377(9779): 1720.

12. Independent Expert Review Group. Every woman, every child, every adolescent: achievements and prospects: the final report of the independent Expert Review Group on Information and Accountability for Women's and Children's health.: World Health Organization, Geneva, Switzerland, 2015.

13. PMNCH. The Partnership for Maternal, Newborn \& Child Health: Placing Healthy Women and Children at the Heart of the Post 2015 Sustainable Development Framework: World Health Organization, Geneva, Switzerland, 2015.

14. Walt G, Shiffman J, Schneider H, Murray SF, Brugha R, Gilson L. 'Doing' health policy analysis: methodological and conceptual reflections and challenges. Health Policy and Planning 2008; 23(5): 308-17.

15. Darmstadt GL, Kinney MV, Chopra M, et al. Who has been caring for the baby? Lancet 2014; 384(9938): 174-88.

16. United Nations: Transforming Our World: The 2030 Agenda for Sustainable Development. Final Draft for the United Nations General Assembly, 25-27 September 2015.: United Nations, New York, NY, USA, 2015.

17. United Nations: Survive, Thrive, Transform. The Global Strategy for Women's, Children's and Adolescents' Health.: United Nations, New York, NY, USA, 2015.

18. World Bank. Business Plan: Global Financing Facility in Support of Every Woman Every Child: World Bank, Washington DC, USA, 2015.

19. de Bernis L, Kinney K, Belizan JM, et al. for the Lancet Ending Preventable Stillbirths study group. Stillbirths: Ending preventable deaths by 2030. The Lancet (Submitted) 2015.

20. Flenady VJ, Wojcieszek AM, Middleton P, et al. for the Lancet Ending Preventable Stillbirth study group. Stillbirths: Recall to action in high-income countries. The Lancet (Submitted) 2015.

21. Heazell AEP, Siassakos D, Blencowe H, et al. for the Lancet Ending Preventable Stillbirth study group. Stillbirths: Global Impact, Cost and Value The Lancet (Submitted) 2015.

22. Shiffman J, Smith S. Generation of political priority for global health initiatives: a framework and case study of maternal mortality. Lancet 2007; 370(9595): 1370-9.

23. Shiffman J. Issue attention in global health: the case of newborn survival. Lancet 2010; 375(9730): 2045-9.

24. Shiffman J, Sultana S. Generating political priority for neonatal mortality reduction in Bangladesh. Am J Public Health 2013; 103(4): 623-31.

25. Smith SL, Shiffman J, Kazembe A. Generating political priority for newborn survival in three low-income countries. Glob Public Health 2014; 9(5): 538-54.

26. Shiffman J, Quissell K, Schmitz HP, et al. A framework on the emergence and effectiveness of global health networks. Health Policy and Planning 2015.

27. Shiffman J. Network advocacy and the emergence of global attention to newborn survival. Health Policy Plan 2015.

28. United Nations. Saving Lives, Protecting Futures. Progress Report on the Global Strategy for Women's and Children's Health: United Nations, New York, NY, USA, 2015.

29. Smith SL, Rodriguez MA. Agenda setting for maternal survival: the power of global health networks and norms. Health Policy and Planning 2015.

30. Walker N. Plausible estimates of stillbirth rates. Lancet 2011; 377(9774): 1292-4.

31. McDougall L, Sharma A, Franz-Vasdeki J, et al. Prioritising women's, children's, and adolescents' health in the post-2015 world. Bmj 2015; 351: h4327.

32. LiST. The Lives Saved Tool - software that predicts survival of mothers and children. 2015. http://livessavedtool.org/ (accessed 08.09.2015 2015).

33. WHO. H4+ partnership: joint country support to improve women's and children's health. Progress Report: World Health Organization, Geneva, Switzerland, 2013. 
34. WHO. Born too soon: the global action report on preterm birth: World Health Organization, Geneva, Switzerland, 2012.

35. WHO. 134th WHO Executive Board Meeting: EB134/17 Add. 1: Newborn health. Report by the Secretariat: World Health Organization, Geneva, Switzerland, 2014.

36. WHO and UNICEF. Every Newborn: an action plan to end preventable deaths: World Health Organization, Geneva, Switzerland, 2014.

37. WHO. Every newborn: an action plan to end preventable deaths. Response to official WHO consultation.: World Health Organization, Geneva, Switzerland, 2014.

38. WHO. Sixty-seventh World Health Assembly: WHA67/2014/REC/1 Resolutions and decisions: WHA67.10 Newborn health action plan: World Health Organization, Geneva, Switzerland, 2014.

39. Independent Expert Review Group (iERG). 2014 Report. Every Woman, Every Child: A Post2015 Vision: World Health Organization, Geneva, Switzerland, 2015.

40. Stenberg K, Axelson $\mathrm{H}$, Sheehan $\mathrm{P}$, et al. Advancing social and economic development by investing in women's and children's health: a new Global Investment Framework. The Lancet; 383(9925): 1333-54.

41. ten Hoope-Bender P, de Bernis L, Campbell J, et al. Improvement of maternal and newborn health through midwifery. The Lancet 2014; 384(9949): 1226-35.

42. UNFPA. The State of the World's Midwifery 2014. A Universal Pathway. A Woman's Right to Health: United Nations Population Fund, New York, NY, USA, 2014.

43. WHO. Strategies toward ending preventable maternal mortality (EPMM): World Health Organization, Geneva, Switzerland, 2015.

44. Chou D, Daelmans B, Jolivet RR, et al. Ending preventable maternal and newborn mortality and stillbirths. Bmj 2015; 351: h4255.

45. Qureshi ZU, Millum J, Blencowe $\mathrm{H}$, et al. Stillbirth should be given greater priority on the global health agenda. Bmj 2015; 351: h4620.

46. Temmerman M, Khosla R, Bhutta ZA, Bustreo F. Towards a new Global Strategy for Women's, Children's and Adolescents' Health. Bmj 2015; 351: h4414.

47. WHO. WHO Statement on antenatal care: World Health Organization, Geneva, Switzerland, 2011.

48. Dowswell T, Carroli G, Duley L, et al. Alternative versus standard packages of antenatal care for low-risk pregnancy. The Cochrane database of systematic reviews 2010; (10): CD000934.

49. Vogel JP, Habib NA, Souza JP, et al. Antenatal care packages with reduced visits and perinatal mortality: a secondary analysis of the WHO Antenatal Care Trial. Reproductive health 2013; 10 : 19.

50. Tunçalp Ö, Were WM, MacLennan C, et al. Quality of care for pregnant women and newborns-the WHO vision. BJOG: An International Journal of Obstetrics \& Gynaecology 2015: n/an/a.

51. WHO and UNICEF. Every Newborn Action Plan: A progress Report. Geneva: World Health Organization, Geneva, Switzerland, 2015.

52. WHO. The prevention and elimination of disrespect and abuse during facility-based childbirth: World Health Organization, Geneva, Switzerland, 2014.

53. United Nations. Commission on the Status of Women. Review and appraisal of the implementation of the Beijing Declaration and Platform for Action and the outcomes of the twentythird special session of the General Assembly. Report of the Secretary-General: United Nations, New York, NY, USA, 2014.

54. United Nations. Progress of the World's Women 2015-2016. Transforming Economies, Realizing Rights: United Nations Enitity for Gender Equality and the Empowerment of Women (UN Women), New York, NY, USA, 2015.

55. UNFPA. ICPD and Human Rights: 20 years of advancing reproductive rights through UN treaty bodies and legal reform: United Nations Population Fund, New York, NY, USA, 2013.

56. WHO. Mental health action plan 2013-2020: World Health Organization, Geneva, Switzerland, 2013. 
57. PMNCH. The Partnership for Maternal, Newborn \& Child Health 2015 Accountability Report. Strengthening Accountability: Achievements and Perspectives for Women's, Children's, and Adolescents' Health.: World Health Organization, Geneva, Switzerland, 2015.

58. WHO. Global Reference List of 100 Core Health Indicators: World Health Organization, Geneva, Switzerland, 2015.

59. WHO. Monitoring of the achievement of the health-related Millennium Development Goals. Report by the Secretariat: World Health Organization, Geneva, Switzerland, 2015.

60. WHO. Sixty-Eight World Health Assembly. Progress Reports WHA68/A68.36: World Health Organization, Geneva, Switzerland, 2015.

61. WHO. ICD-10: International statistical classification of diseases and related health problems-instruction manual: World Health Organization, Geneva, Switzerland, 2004.

62. Reinebrant HE, Zheyi T, Leisher S, et al. Causes of stillbirth globally - burden in high- and lowresource settings. BMC Pregnancy Childbirth (Submitted to Ending Preventable Stillbirths Supplement) 2015.

63. Leisher S, Allanson E, Blencowe H, et al. Seeking order amidst chaos: A systematic review of classification systems for causes of stillbirth and neonatal death, 2009-2014. BMC Pregnancy Childbirth (Submitted to Ending Preventable Stillbirths Supplement) 2015.

64. Reinebrant H. Consensus on the important characteristics of a good global classification system for perinatal deaths. BMC Pregnancy Childbirth (Submitted to Ending Preventable Stillbirths Supplement) 2015.

65. WHO. The WHO application of ICD-10 to deaths during pregnancy, childbirth and puerperium: ICD MM: World Health Organization, Geneva, Switzerland, 2012.

66. Allanson E, Tunçalp Ö, Chou D, et al. Perinatal mortality: WHO Application of ICD 10 to perinatal deaths. The Lancet (Submitted) 2015.

67. Nausheen S, Soofi SB, Sadiq K, et al. Validation of verbal autopsy tool for ascertaining the causes of stillbirth. PLoS One 2013; 8(10): e76933.

68. Leitao J, Chandramohan D, Byass $\mathrm{P}$, et al. Revising the WHO verbal autopsy instrument to facilitate routine cause-of-death monitoring. Glob Health Action 2013; 6: 21518.

69. Travis P, Bennett S, Haines PA, et al. Overcoming health-systems constraints to achieve the Millennium Development Goals. Lancet 2004; 364(9437): 900-6.

70. Saving Newborn Lives. Meeting Report: Newborn Health Indicators Working Group Meeting March 18-19, 2015. Save the Children, London, UK, 2015.

71. Frøen JF, Flenady VJ, Myhre S, et al. Electronic Health Registries for Mothers and their Children. Lancet Global Health (Invited submission in conjunction with Ending Preventable Stillbirth series) 2015.

72. Frøen JF, Myhre S, Frost MJ, et al. eRegistries: Electronic registries for maternal and child health. BMC Pregnancy Childbirth (Submitted to Ending Preventable Stillbirths Supplement) 2015.

73. Flenady VJ, Wojcieszek AM, Fjeldheim I, et al. eRegistries: Indicators for the WHO Essential Interventions for reproductive, maternal, newborn and child health. BMC Pregnancy Childbirth (Submitted to Ending Preventable Stillbirths Supplement) 2015.

74. Frost MJ, Hodne Titlestad O, Mehl G, et al. eRegistries: Architecture and Free Open Source Software for Maternal and Child Health Registries. BMC Pregnancy Childbirth (Submitted to Ending Preventable Stillbirths Supplement) 2015.

75. Myhre S, Kaye J, Aanestad M, et al. eRegistries: Governance for maternal and child health registries. BMC Pregnancy Childbirth (Submitted to Ending Preventable Stillbirths Supplement) 2015.

76. Frost MJ, Hodne Titlestad O, Lewis J, Mehl G, Frøen JF. eRegistries: Architecture and Free Open Source Software for maternal and child health Registries. BMC Pregnancy Childbirth (Submitted to Ending Preventable Stillbirths Supplement) 2015.

77. WHO. Accountability for women's and children's health: report on progress to May 2014: World Health Organization, Geneva, Switzerland, 2014. 
78. Labrique AB, Vasudevan L, Kochi E, Fabricant R, Mehl G. mHealth innovations as health system strengthening tools: 12 common applications and a visual framework. Global health, science and practice $2013 ; 1(2)$ : 160-71.

79. Mehl G, Labrique A. Prioritizing integrated mHealth strategies for universal health coverage. Science 2014; 345(6202): 1284-7.

80. World Bank, USAID and WHO. Health Measurement and Accountability Post 2015: Five-Point Call to Action.: MA4Health, Washington, DC, USA, 2015.

81. World Bank, USAID and WHO: The Roadmap for Health Measurement and Accountability: MA4Health, Washington, DC, USA, 2015.

82. Chou D, Daelmans B, Rima J, Kinney K. Ending Preventable Maternal and Newborn Mortality and Stillbirths. Effective interventions and strategies. BMJ (submitted) 2015.

83. Pattinson RC, Kerber K, Waiswa P, et al. Perinatal mortality audit: counting, accountability, and overcoming challenges in scaling up in low- and middle-income countries. International journal of gynaecology and obstetrics: the official organ of the International Federation of Gynaecology and Obstetrics 2009; 107 Suppl 1: S113-21, S21-2.

84. Kerber K, Mathai $\mathrm{M}$, Lewis $\mathrm{G}$, et al. Counting every stillbirth and neonatal death to improve quality of care for every pregnant woman and her baby. BMC pregnancy and childbirth in press. 85. Allanson E, Pattinson RC. Quality of care audit and improving perinatal mortality. Does it work? Bulletin of the World Health Organization 2015; 93: 424-8.

86. Michalow J, Chola L, McGee S, et al. Triple return on investment: the cost and impact of 13 interventions that could prevent stillbirths and save the lives of mothers and babies in South Africa. BMC pregnancy and childbirth 2015; 15: 39.

87. Fernandes QF, Wagenaar BH, Anselmi L, Pfeiffer J, Gloyd S, Sherr K. Effects of health-system strengthening on under-5, infant, and neonatal mortality: 11-year provincial-level time-series analyses in Mozambique. The Lancet Global Health 2014; 2(8): e468-e77.

88. McClure EM, Pasha O, Goudar SS, et al. Epidemiology of stillbirth in low-middle income countries: A Global Network Study. Acta obstetricia et gynecologica Scandinavica 2011; 90(12): 137985.

89. Saastad E, Vangen S, Frøen JF. Suboptimal care in stillbirths - a retrospective audit study. Acta Obstet Gynecol Scand 2007; 86(4): 444-50.

90. WHO. Towards a monitoring framework with targets and indicators for the health goals of the post-2015 Sustainable Development Goals: World Health Organization, Geneva, Switzerland, 2015. 


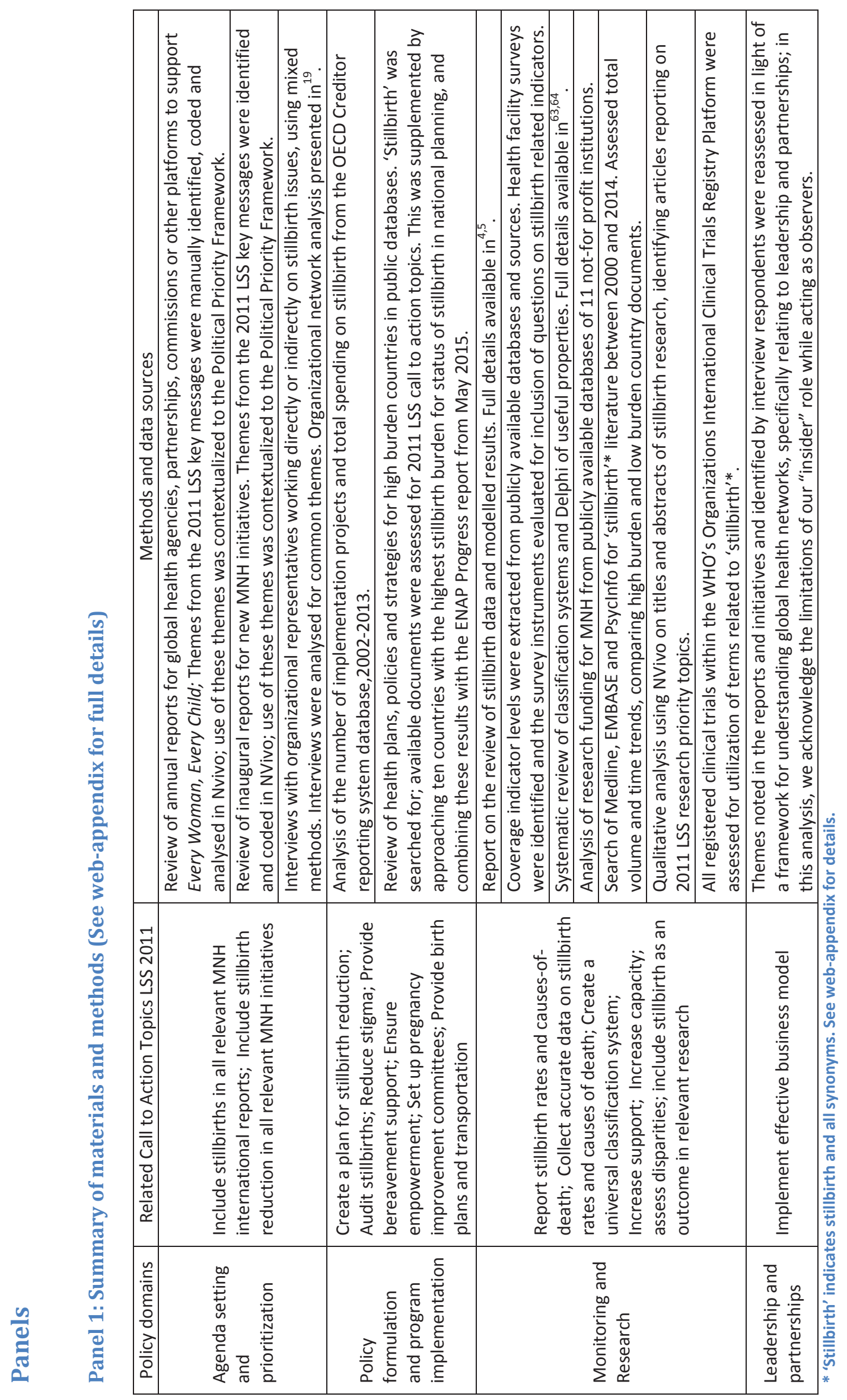


Agenda setting and prioritization: Priority for stillbirth prevention has firmly emerged in the convergence of priorities for the mother and her baby, and is integrated in global initiatives such as Every Newborn Action Plan and the Global Strategy for Women's, Children's and Adolescent's Health.

Policy formulation: Policy and guidance that addresses the entire continuum of prenatal health and survival through high quality antenatal care and care at birth are being developed, but there is no progress in efforts to address stigma and taboos, or in support to affected women and families. of implementing programs and targets that, if achieved, would prevent one in four stillbirths globally. Still, in most countries, implementation of the recommended community actions and health interventions for prenatal health is generally low. Hardly any funding has been disbursed. Monitoring and accountability: Routine data on stillbirths are improving, but accountability for high quality antenatal care and care at birth requires antepartum and intrapartum stillbirth be core indicators. Health information systems and indicator development show promise, but currently minimal data is available on effective coverage of the essential interventions.

Research priorities: There is progress in research efforts for high-burden settings, but, relative to the burden they represent, stillbirth research continues to be under-developed and under-financed. Leadership and partnerships: The network of organizations addressing stillbirth is expanding, but underutilized and reliant on individuals rather than the core global governance structure of UN agencies and partnerships. They must seize this historic opportunity to partner for prenatal health and survival. 
Panel 3: The Indian Newborn Action Plan

In September 2014, the Indian Ministry of Health and Family Welfare (MOHFW) adopted the Indian Newborn Action Plan (INAP) which includes a 'single-digit' stillbirth target for 2030 - the first national stillbirth prevention target. The plan is based on integrated interventions in antenatal care and care at birth for stillbirth prevention and newborn survival, linked to an ongoing roll-out of a national stillbirth monitoring scheme capturing rates and causes, and supported by a scientific coordinating center, and a Technical Advisory Committee under the leadership of the Joint Secretary of the MOHFW.

The convergence of three streams of scientific and public health work and advocacy were instrumental in this development: First, India committed to a 2011 WHO initiative for the elimination of mother-to-child-transmission of HIV and syphilis. To monitor and achieve the goals to eliminate congenital syphilis, it was acknowledged that stillbirth was a key indicator for mother-to-child transmission and information on cause-specific stillbirth rates were needed. With support from the WHO regional office for South-East Asia and the US Centers for Disease Control, 10 sentinel sites were organized for stillbirth monitoring, providing data on the burden and causes of stillbirth. Second, mortality statistics demonstrated that $56 \%$ of under- 5 child mortality were newborns. To progress in reducing child mortality in India, this became a priority in professional communities. There was evidence from research and inconsistent national stillbirth estimates that a significant proportion of newborn deaths were reported as stillbirths rather than an unsuccessful neonatal resuscitation, and a strong sense emerged that stillbirths needed to be monitored together with newborn deaths to provide better data and indicators on care provision for babies and mothers to support further improvements. Third, advocacy by the 2011 Lancet Stillbirth Series and the WHO regional office increased awareness of stillbirth, and experts in obstetrics and gynecology became champions for stillbirth prevention in the national discussions. With the political endorsement and support for the Every Newborn Action Plan, ongoing efforts by professionals and scientists converged with political priority to include stillbirth targets and scale up monitoring under INAP. 
Several elements were important in facilitating this development. Evidence emerged that the vast majority of stillbirths were preventable with simple interventions similar to those for the prevention of newborn mortality. There was national consensus that better data were needed on babies dying as newborns or in stillbirths, and that these data were important indicators of care, in particular in the setting of reduced maternal mortality ratios. There was consensus on definitions of early and late stillbirths, and on the use of an adapted CODAC classification of causes. The sentinel sites had proven the feasibility of stillbirth monitoring as a template for national scale up of monitoring that would support the ongoing national child screening program for birth defects, in particular given the increase of facility deliveries beyond $80 \%$ promoted by the MOHFW. And finally, the existence of national champions among professionals supporting global advocacy to create the political support for INAP stillbirth targets and monitoring. 
Figure legend: The heuristic approach to policy analysis ${ }^{15}$ (blue) linked to the 2011 Lancet Stillbirth priority $^{22}$ (dark blue).

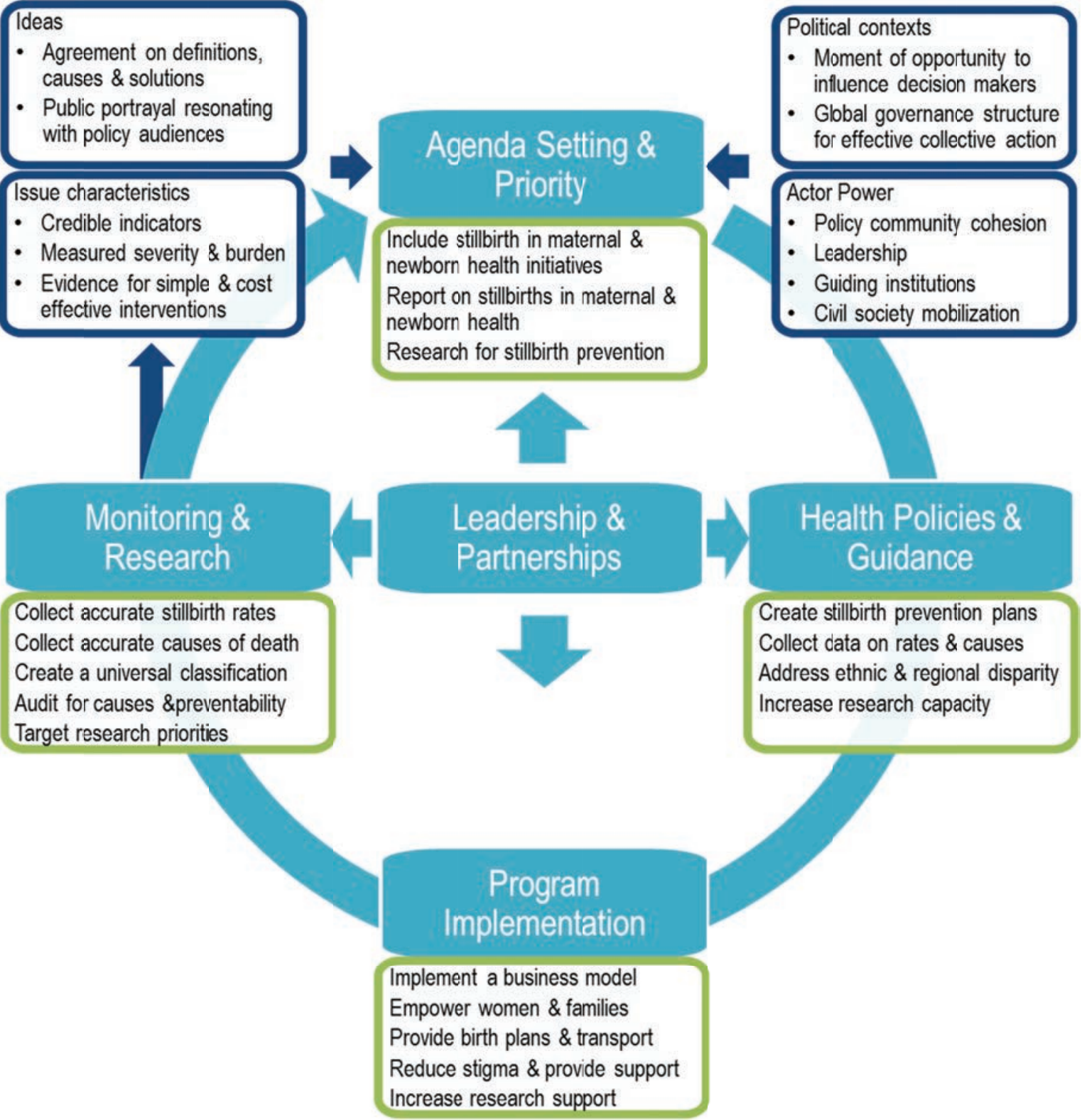


Figure legend: The 500 most commonly used thematic words in annual reports of work from global

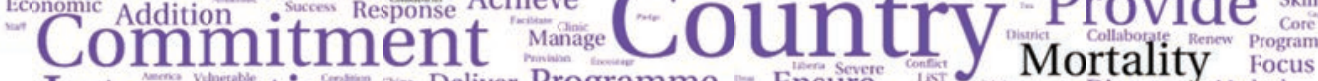
Intervention Deliver Programme Ensure

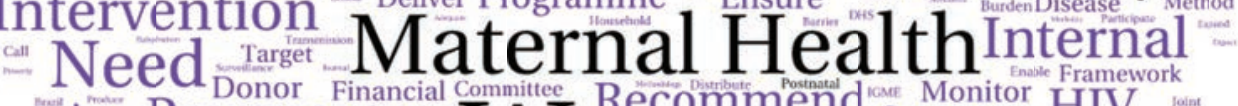
Area Progress - scale committee Recommend Monitor HIV

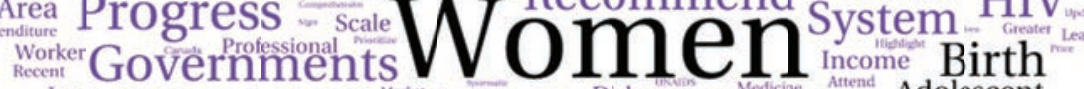

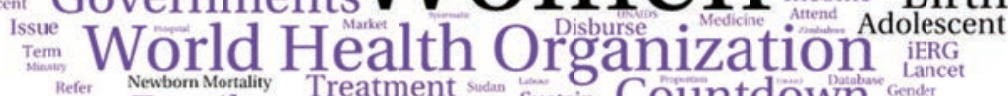

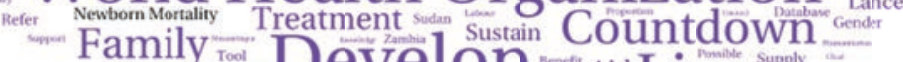




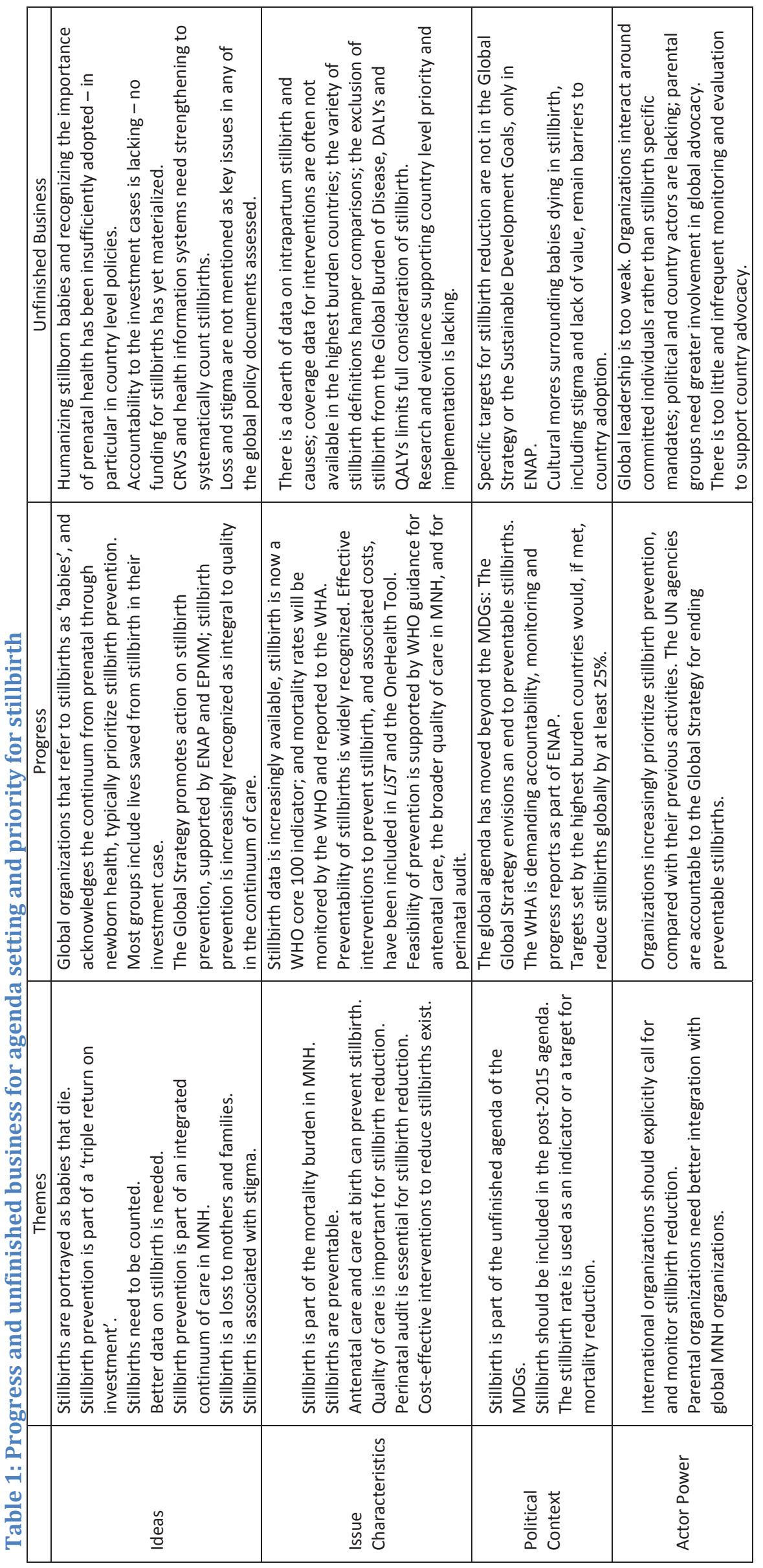




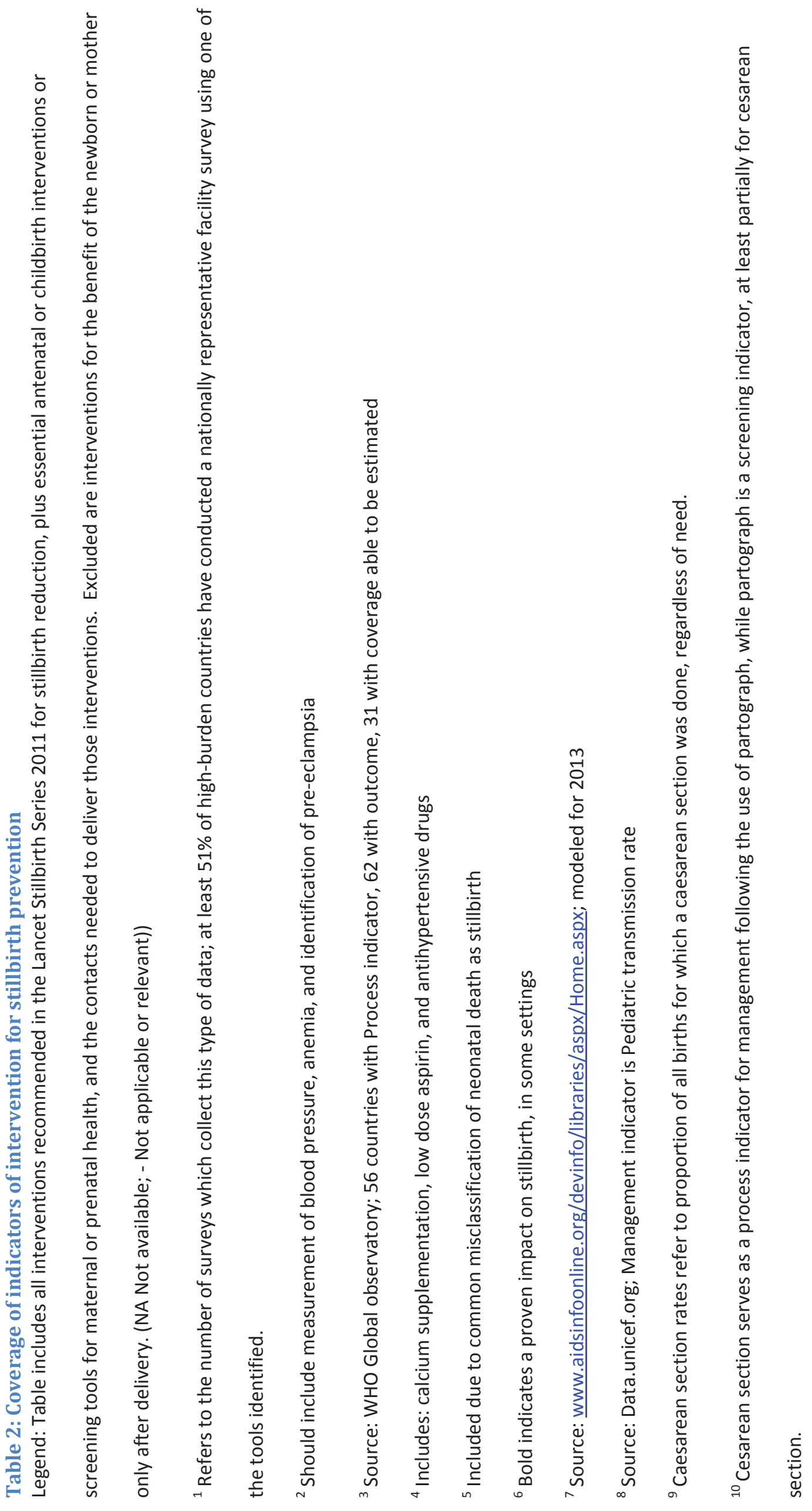




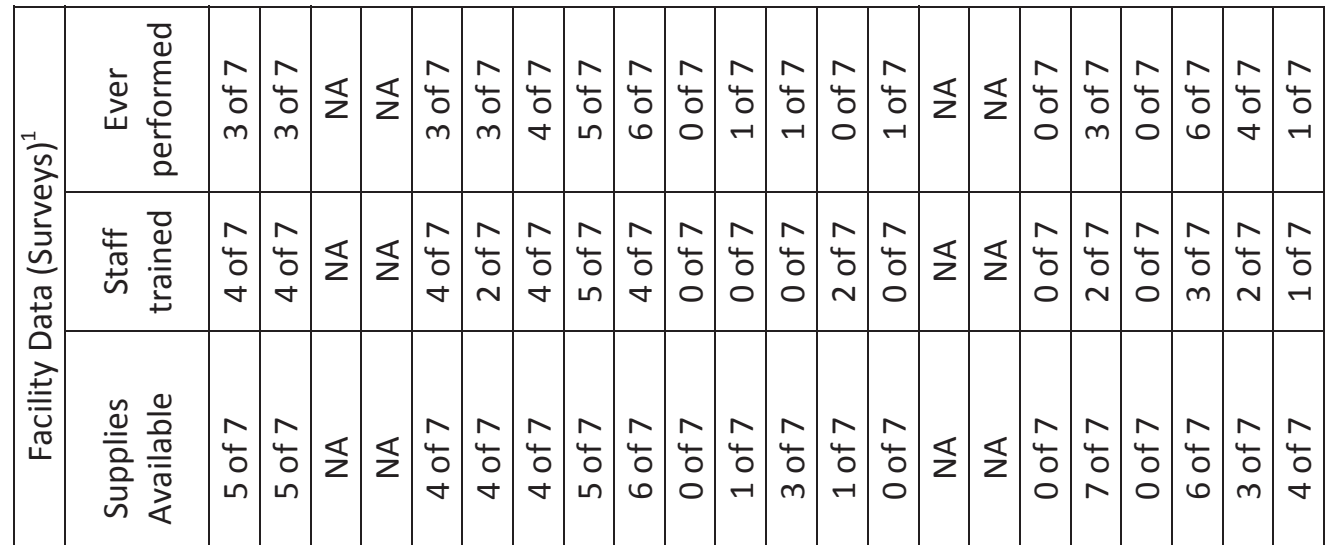

\begin{tabular}{|c|c|c|}
\hline 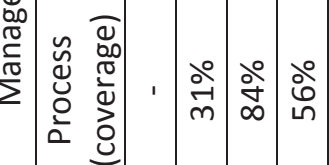 & 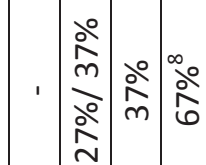 & | \\
\hline$\frac{\pi}{2} \frac{1}{2} \frac{1}{2}$ & 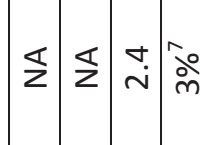 & $\left\{\frac{1}{2} \frac{1}{2}\right.$ \\
\hline 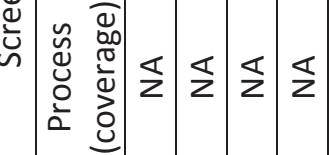 & $\frac{1}{2} \frac{1}{2} \frac{\infty}{7}$. & $\frac{1}{2} \frac{\pi}{2}$ \\
\hline
\end{tabular}

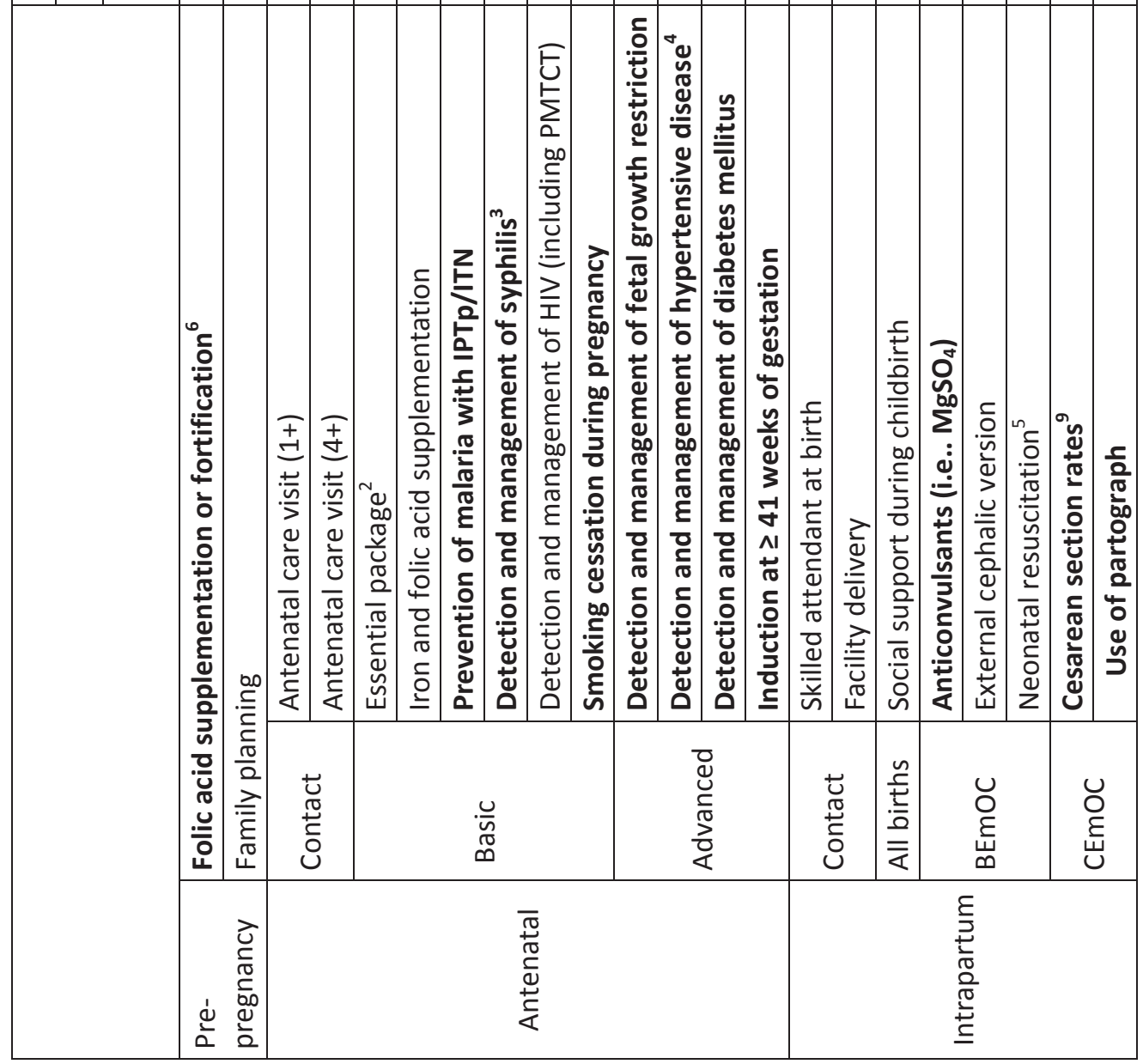


